\title{
ANÁLISE DOS GASTOS AMBIENTAIS NO SETOR PÚBLICO BRASILEIRO: CARACTERÍSTICAS E PROPOSTAS ALTERNATIVAS
}

\author{
Juarez Paulo Tridapalli \\ Doutor em Engenharia de Transportes pela Universidade Federal do Rio de Janeiro - UFRJ \\ Professor da Universidade Estadual de Londrina - UEL \\ jtridapalli@uel.br \\ Benilson Borinelli \\ Doutor em Ciências Sociais pela Universidade Estadual de Campinas - UNICAMP \\ Professor da Universidade Estadual de Londrina - UEL \\ bborinelli@hotmail.com
}

\author{
Maria Fátima Sales de Souza Campos \\ Doutora em Economia pela Universidade Federal de Pernambuco - UFPE \\ Professora da Universidade Estadual de Londrina - UEL \\ mariadefatima.campos@uol.com.br \\ Cristiane de Castro \\ Bacharel em Administração pela Universidade Estadual de Londrina - UEL \\ cris.amcl@hotmail.com
}

\section{RESUMO}

O objetivo deste trabalho é apresentar um levantamento das principais formas de análise de gastos ambientais no setor público e, complementarmente, propor algumas formas alternativas de estudo desses gastos. Esta investigação tem caráter exploratório, bibliográfico e documental. Os resultados mostram que pesquisas sobre gastos ambientais no Brasil tiveram início após o final dos anos 1990, destacandose o nível de análise federal e as despesas totais, por função e por subfunções da gestão ambiental, e o uso dos indicadores de valores absoluto e relativo por função, proporção entre despesa orçada e liquidada. Já em nível internacional é mais frequente o uso de indicadores econômicos para analisar os gastos ambientais, com destaque para a participação dos gastos ambientais do setor público, no PIB, no total dos gastos públicos e per capita. Vale ressaltar que é possível e necessário avançar consideravelmente na análise quantitativa e qualitativa dos gastos ambientais, desenvolvendo-se estudos comparativos e históricos que procurem investigar se e como variáveis econômicas, sociais, políticas e territoriais influenciam o comportamento dos gastos ambientais do país, de estados e de municípios.

Palavras-chave: Análise de gastos; Gastos públicos; Política ambiental.

\section{ANALYSIS OF ENVIRONMENTAL EXPENDITURES IN BRAZILIAN PUBLIC SECTOR: CHARACTERISTICS AND ALTERNATIVE PROPOSALS}

\begin{abstract}
The aim of this paper is to present a survey of the main forms of analysis of environmental expenses in the public sector and additionally propose some alternative ways to study them. The research conducted was exploratory, bibliographic and documentary. The results show that research on environmental expenses in Brazil began after the late 1990s, especially on the federal level of analysis and total expenditure, by function and sub-functions of environmental management and use of absolute and relative indicators for function, the ratio between budgeted expenditure and settled expenditure. At the international level economic indicators are more frequently used to analyze environmental costs particularly the participation of environmental spending in the public sector in the GDP and in the total public spending and per capita. It is possible and necessary to make considerable progress in quantitative and qualitative analysis of environmental costs, develop comparative and historical studies that seek to investigate whether and how economic, social, political and territorial variables influence the behavior of environmental spending in the country, states and municipalities.
\end{abstract}

Keywords: Public Spending; Environmental Policy; Analysis of expenses. 


\section{INTRODUÇÃO}

O objetivo deste artigo é apresentar um levantamento das principais formas de análise de gastos ambientais no setor público. Desde o surgimento da política ambiental moderna, nos anos 1960, o problema de como financiá-la tem sido cada vez mais um tema recorrente nos fóruns e debates internacionais sobre como alcançar o desenvolvimento sustentável. Neste contexto, financiar políticas ambientais efetivas, portanto, tem se caracterizado como um fator crítico para se conter a degradação ambiental do planeta. Neste aspecto, o acompanhamento e a avaliação dos gastos ambientais vêm crescendo em importância, como meio de verificar, ao longo do tempo, a prioridade destes gastos em relação a outros entre níveis de governo e sociedades e a sua eficácia.

Desde a década de 1990, vários países e organizações internacionais têm realizado esforços para medir e monitorar os gastos em gestão ambiental e têm buscado respostas para as seguintes perguntas: qual é o custo da proteção do meio ambiente? Os gastos refletem uma resposta da sociedade aos problemas ambientais? (Bárcena et al., 2002). Em razão destas questões, em 1998, a Comissão das Nações Unidas para o Desenvolvimento Sustentável estabeleceu um conjunto de procedimentos e princípios internacionalmente aceitos para a contabilidade ambiental (Jasch, 2003).

Embora ainda sejam insuficientes, os gastos públicos e privados em gestão ambiental cresceram significativamente em volume nas últimas décadas, em decorrência da constatação científica da dimensão global dos danos ambientais e da pressão de movimentos ambientais. Esse fenômeno também foi percebido em países em desenvolvimento, como o Brasil, onde os gastos em meio ambiente são fortemente dependentes do poder público (Young, 2002). Contudo, o acompanhamento e a análise dos gastos públicos em meio ambiente ainda são bastante restritos no Brasil, comparativamente à experiência internacional e diante do contexto nacional mais recente, o que gerou condições mais favoráveis ao controle público dos gastos governamentais.

O processo de democratização e a crise dos modelos de Estado centralizadores, a partir dos anos 1980, fomentaram a criação de novas institucionalidades, caracterizadas, sobretudo, pelo maior grau de participação da sociedade na formulação, implementação e avaliação das políticas públicas. Em complemento, os avanços nas tecnologia de informação, por meio do incrível aumento da capacidade de armazenamento, processamento e disseminação de um grande volume de dados, facilitaram as condições para uma maior transparência das ações governamentais.

Neste contexto, busca-se, com este artigo, contribuir para o debate sobre as possibilidades e a relevância de estudos a respeito do gasto público em meio ambiente no país, de sorte a aumentar a transparência e o uso mais efetivo de dados públicos para a avaliação crítica e social e a promoção da maior efetividade das políticas ambientais. Isto é extremamente relevante, tendo em vista que as demandas para o desenvolvimento sustentável são cada vez maiores, diante do cenário que combina a histórica baixa efetividade da política ambiental e as tendências de agravamento do quadro de riscos e tragédias associadas ao processo de degradação ambiental no país e no planeta.

Inicia-se este texto apresentando conceitos e ideias centrais sobre a análise de gastos públicos em meio ambiente. Em seguida, são descritos os principais estudos sobre esses gastos no Brasil e algumas contribuições da literatura internacional. Na quarta parte, a título de ilustração, são sugeridas análises alternativas de gastos ambientais, a partir do conjunto de dados disponíveis no Brasil. Por fim, as especificidades e a dimensão política da política ambiental são apontadas como aspectos qualitativos que devem ser contemplados na análise dos gastos ambientais.

\section{GASTOS PÚBLICOS EM POLÍTICA AMBIENTAL}

Nesta seção, são apresentados alguns conceitos centrais para introduzir e demarcar a discussão sobre a análise de gastos públicos em meio ambiente. Trata-se de uma breve explanação sobre a ascensão da política ambiental como resposta à crise ambiental em nível nacional e internacional e a expressão deste processo na demonstração dos gastos públicos no Brasil.

Revista de Gestão Social e Ambiental - RGSA, São Paulo, v. 5, n. 2, p. 79-95, mai./ago. 2011. 
Desde os anos 1960, a degradação do meio ambiente vem se impingindo sobre os Estados de diversos países, alcançando, desde então, o status de política pública específica. Diante da gravidade deste quadro, fundava-se, assim, o campo da política ambiental como novo setor de regulação estatal.

Em geral, tal política foi uma resposta às pressões nacionais e internacionais por maior atenção aos efeitos dos modelos de produção e consumo pregados pela industrialização e o desenvolvimentismo.

Segundo Diamond (2005), os processos ambientais que minaram as sociedades do passado e minam as sociedades do presente são doze: desmatamento, destruição do habitat, problemas com o solo (erosão, salinização, perda de fertilidade), problemas com o controle de água, sobrecaça, sobrepesca, introdução de espécies estranhas ao meio ambiente nativo, crescimento demográfico, mudanças climáticas provocadas pelo homem, acúmulo de produtos químicos tóxicos no meio ambiente, carência de fontes de energia e utilização total da capacidade fotossintética. Embora a ocorrência e os efeitos destes processos variem enormemente entre as sociedades, a eclosão da política ambiental moderna foi um reconhecimento da atividade humana como uma das principais causas da crise ambiental, do escopo global e do caráter ameaçador à vida no planeta.

Inicialmente, pode-se partir de um conceito amplo de política ambiental, entendida como o "[...] conjunto de definições adotadas pelas autoridades, que condicionam e determinam de algum modo o comportamento das pessoas, das empresas e das próprias repartições públicas no que se refere ao uso, manejo e conservação dos recursos naturais e a ação dos serviços ambientais que dispõe a sociedade." (Bustamante \& Torres, 1990, p. 110).

Num sentido estrito, as políticas ambientais são as que apresentam uma preocupação explícita quanto à proteção, à conservação e ao uso dos recursos naturais e do meio ambiente. Essas políticas, expressas na legislação e na organização institucional correspondente, definem os instrumentos de intervenção do Estado na administração dos recursos e da qualidade do meio ambiente. (Monosowski, 1989). Os dois conceitos retratam, que, em qualquer um dos casos, a política ambiental engloba um campo extremamente amplo e complexo, o que, como será exposto mais a frente, lhe confere certas especificidades quando comparada a outras políticas.

Seja nas orientações mais liberais, seja nas orientações mais tecnocráticas e centralizadoras, o Estado desempenha papel fundamental e insubstituível no processo de regulação ambiental como representante do interesse público e garantidor de direitos ambientais. Para fazer valer a política ambiental, o Estado pode lançar mão de um conjunto de instrumentos que combinam ações de comando e controle, como normas e legislações, zoneamentos, licenciamentos e fiscalização e de instrumentos econômicos, tais como taxas, impostos, permissões negociáveis de utilização, créditos subsidiados, isenções de impostos e outras facilidades contábeis para efeito da redução da carga fiscal. Muitos destes instrumentos, inclusive, são defendidos como fontes para financiar a política ambiental.

De acordo com O’Donnell (2008), para demarcar conceitualmente a institucionalização da política ambiental, cabe destacar duas dimensões formais do Estado moderno: a) como conjunto de burocracias, em que o Estado se mostra como organizações complexas e hierarquicamente orientadas que têm responsabilidades estabelecidas a alcançar ou proteger algum aspecto do bem, ou interesse (público ou comum), no qual a eficácia do Estado depende de em que medida suas burocracias cumprem essas responsabilidades e; b) como sistema legal, no qual o Estado representa um conjunto de regras que penetram e codeterminam numerosas relações sociais. Quanto mais as burocracias estatais se pautem por responsabilidades e faculdades legalmente estabelecidas, maior a efetividade do sistema legal do Estado.

Em que pese os avanços, retrocessos e diferentes times nos mais variados países, a institucionalização da política ambiental seguiu, basicamente, a rotina da formação das burocracias públicas modernas, com a definição de um arcabouço jurídico, de um formato organizacional para a agência ambiental e alocação de recursos humanos, materiais e orçamentários. 
Existem fragmentos de uma política ambiental no Brasil desde o período colonial. Entretanto, foi a partir do período republicano que as ações estatais passaram a ter mais consistência e ser vinculadas também às preocupações de ordem coletiva e pública. Foi em 1972, após e com a Conferência de Estocolmo, que as preocupações ambientais tornaram-se mais intensas e próximas do formato institucional da política ambiental moderna. Desde então, assistiu-se à formação de uma considerável estrutura institucional do meio ambiente, com a criação da Secretaria Especial do Meio Ambiente em nível federal, em 1973, e de diversas agências estaduais e municipais especializadas. Em 1981, teve-se o marco legal, encabeçado pela Lei 6.938, de 31 de agosto de 1981, que estabeleceu a Política Nacional do Meio Ambiente. Em 1988, foram estabelecidos preceitos constitucionais de cunho ambiental na Constituição Federal, a exemplo da incorporação do conceito de desenvolvimento sustentável; da corresponsabilidade dos entes federativos pela qualidade ambiental; e o direito de todos a um meio ambiente equilibrado.

Essa nova estrutura institucional impactou os gastos públicos no país, por um lado, como nova destinação de recursos públicos e, mais adiante, por outro, também como uma nova fonte de recursos públicos. Diante dos objetivos deste artigo,vamos nos deter, sobretudo, no primeiro caso, destacando a seguir algumas noções sobre gastos públicos e ambientais e a sua forma de demonstração pelo poder público no Brasil.

Giambiagi e Além (2007) conceituam gastos públicos como os dispêndios dos governos, na forma de custeio, investimentos, transferências e inversões financeiras, com o objetivo de cumprir as três funções governamentais: alocativa, distributiva e estabilizadora, balizadas pelo sistema legal.

Para fazer frente às despesas governamentais, o Estado conta com receitas tributárias; de contribuições; patrimoniais; industriais; agropecuárias e de serviços. Quanto à origem de captação dessas receitas, elas podem ser próprias ou de transferências, que são aquelas provenientes do repasse de recursos captados por outras instituições ou instâncias de governo. (Rezende, 2001)

Contudo, embora seja fortemente revestida de um caráter técnico e legal, a discussão e a compreensão do fenômeno "gastos públicos" são permeados por questões administrativas, políticas e ideológicas. Tais gastos expressam, em última instância, como e onde são recolhidos e alocados recursos escassos, provenientes do esforço coletivo de uma sociedade. Implicitamente, são definidos, nesse momento, quais paradigmas sociais e econômicos, projetos, setores, regiões, políticas e pessoas são efetivamente priorizadas ou não.

Enquanto tal, a alocação de recursos financeiros públicos ou a falta desta - com os recursos de poder, que dizem respeito à centralidade político-decisória da agência, e os recursos institucionais referentes, por exemplo, à apropriação segura de uma área de decisões - é uma das formas de determinar o seu grau de poder e autonomia em relação às demais alternativas (Abranches, 1987).

Um clima conflituoso e contencioso do gasto público está presente nos processos que antecedem o gasto propriamente dito, da definição de tetos para as unidades administrativas pelo Poder Executivo, passando pelas negociações com membros do Poder Legislativo e do Poder Judiciário para a aprovação do Orçamento, até os processos que orientam a execução orçamentária. $\mathrm{Na}$ última parte deste artigo, serão ilustradas algumas implicações da dimensão dos gastos públicos para o caso dos gastos públicos em meio ambiente.

Tais gastos compreendem aqueles inerentes às funções constitucionais do Estado relacionadas à preservação e recuperação ambiental e à garantia de direitos ambientais. No caso brasileiro, por exemplo, gastos públicos em custeio e investimentos são realizados para a administração, operação e suporte dos órgãos encarregados de controle ambiental, controle da poluição do ar e do som, políticas e programas de reflorestamento, monitoramento de áreas degradadas, obras de prevenção a secas, levantamentos e serviços de remoção de lixo em áreas de proteção e reservas ambientais (florestas, lagoas, rios etc.).

Os recursos destinados ao setor ambiental podem originar de um número variado de fontes, tais como recursos ordinários do tesouro, compensações financeiras pela exploração de recursos 
naturais, taxas e multas pelo exercício de poder de polícia, empréstimos e doações internacionais e convênios com outros órgãos públicos. Naturalmente, essas fontes e o peso de cada uma no montante dos recursos à disposição dos órgãos e programas ambientais variam consideravelmente, em razão do nível de governo, do tamanho e riqueza do estado, da gravidade percebida dos problemas ambientais etc.

A análise e o acompanhamento dos gastos públicos no Brasil foram enormemente favorecidos pela aprovação da Lei Complementar $n^{\circ} 101$, de 4 de maio de 2000, intitulada Lei de Responsabilidade Fiscal (LRF) e pelas mudanças na apresentação da contabilidade pública no final dos anos 1990. (Secretaria do Orçamento Federal [SOF], 2009).

A LRF criou condições para a implantação de uma nova cultura gerencial na gestão dos recursos públicos e incentivou o exercício pleno da cidadania, especialmente no que se refere à participação do contribuinte no processo de acompanhamento da aplicação dos recursos públicos e de avaliação dos seus resultados. Estabeleceu regras que obrigam os entes federativos a apresentarem demonstrativos fiscais, que devem ser publicados em meio eletrônico, para que se tenha amplo acesso público, criando mecanismos de disponibilização das contas públicas consolidadas, inclusive de forma detalhada por função e subfunção. (Loureiro, Teixeira \& Prado, 2008). Isso permite, analisar os gastos públicos em gestão ambiental com profundidade e extensão (Federal, Estadual e Municipal) como jamais foi possível.

Entretanto, para que haja uma transparência efetiva, além das informações estarem disponíveis, é necessário que elas estejam em uma linguagem acessível. Mais do que isso, é preciso avançar no desenvolvimento de informações e indicadores que subsidiem e deem consistência para as tomadas de decisão das demandas dos atores sociais e da formulação e avaliação de políticas públicas.

A seguir, apresenta-se uma síntese da experiência brasileira e internacional de como os gastos ambientais do setor público vêm sendo analisados e apresentados.

\section{A EXPERIÊNCIA DE AVALIAÇÃO DOS GASTOS AMBIENTAIS REALIZADOS PELO SETOR PÚBLICO NO BRASIL E ALGUMAS CONTRIBUIÇÕES DA LITERATURA INTERNACIONAL}

Nesta seção, será apresentada uma síntese dos estudos sobre gastos ambientais realizados no Brasil. Tendo em vista que existem poucos estudos sobre este tema no país, tanto na iniciativa privada quanto no setor público, optou-se por sintetizar as informações no Quadro 1, focando, especificamente: o período de análise; o nível da análise (se consolidado, federal, estadual ou municipal); a esfera dos gastos (total, por função, por subfunção, institucional, política setorial) e os indicadores utilizados para análise.

\begin{tabular}{|c|c|c|c|c|c|}
\hline Autor & Ano & Período & Nível de análise & Tipos gastos & Indicadores \\
\hline IBGE & 2001 & $\begin{array}{c}1996- \\
1998\end{array}$ & $\begin{array}{l}\text { - Consolidado } \\
\text { - Federal } \\
\text { - Estadual } \\
\text { - Municipal }\end{array}$ & $\begin{array}{l}\text { Total e por } \\
\text { função. }\end{array}$ & $\begin{array}{l}\text { Valor absoluto e relativo por } \\
\text { função. }\end{array}$ \\
\hline $\begin{array}{l}\text { Young e } \\
\text { Roncisvalle }\end{array}$ & 2002 & $\begin{array}{l}1992- \\
2002\end{array}$ & $\begin{array}{ll}\text { - } & \text { Federal } \\
\text { - } & \text { Estadual } \\
\text { - } & \text { Municipal }\end{array}$ & $\begin{array}{l}\text { Total, por } \\
\text { funções, por } \\
\text { subfunções, } \\
\text { institucional. }\end{array}$ & $\begin{array}{l}\text { Proporção entre valores } \\
\text { autorizados e executados; } \\
\text { valores absolutos e } \\
\text { proporcionais de despesas; } \\
\text { despesas por instituições; } \\
\text { distribuição regional dos } \\
\text { gastos. }\end{array}$ \\
\hline Carneiro & 2008 & $2000-$ & - Federal & Total, por & Proporção entre despesa \\
\hline
\end{tabular}

Revista de Gestão Social e Ambiental - RGSA, São Paulo, v. 5, n. 2, p. 79-95, mai./ago. 2011. 


\begin{tabular}{|c|c|c|c|c|c|}
\hline & & 2006 & & $\begin{array}{l}\text { função, por } \\
\text { subfunções, } \\
\text { institucional }\end{array}$ & $\begin{array}{l}\text { orçada e liquidada; } \\
\text { participação na despesa } \\
\text { liquidada total. }\end{array}$ \\
\hline $\begin{array}{l}\text { Lemos, } \\
\text { Young e } \\
\text { Geluda }\end{array}$ & 2005 & $\begin{array}{l}2000- \\
2005\end{array}$ & $\begin{array}{ll}\text { - } & \text { Federal } \\
\text { - } & \text { Estadual } \\
\text { - } & \text { Municipal }\end{array}$ & $\begin{array}{l}\text { Função e por } \\
\text { subfunção }\end{array}$ & $\begin{array}{l}\text { Valor absoluto e percentual } \\
\text { dos gastos; despesas } \\
\text { liquidadas; participação dos } \\
\text { gastos em gestão ambiental } \\
\text { na despesa liquidada total. }\end{array}$ \\
\hline IBGE/IDS & 2008 & $\begin{array}{l}1996- \\
2004\end{array}$ & $\begin{array}{ll}\text { - } & \text { Federal } \\
\text { - Estadual } \\
\text { - } & \text { Municipal }\end{array}$ & Total & $\begin{array}{l}\text { Relação entre as despesas } \\
\text { ambientais e o total das } \\
\text { despesas públicas, em } \\
\text { valores absolutos e em } \\
\text { percentual. }\end{array}$ \\
\hline $\begin{array}{l}\text { Dutra, } \\
\text { Oliveira e } \\
\text { Prado }\end{array}$ & 2006 & $\begin{array}{l}2000- \\
2005\end{array}$ & - Federal & $\begin{array}{c}\text { Total, } \\
\text { institucional, } \\
\text { políticas } \\
\text { setoriais. }\end{array}$ & $\begin{array}{l}\text { Comparativo entre: } \\
\text { - despesa autorizada e } \\
\text { receita primária da União; } \\
\text { - despesa autorizada e a } \\
\text { despesa destinada para } \\
\text { reserva de contingência e } \\
\text { serviços da dívida externa; } \\
\text { - evolução da despesa } \\
\text { empenhada e o número de } \\
\text { hectares de unidades de } \\
\text { conservação de } \\
\text { administração direta do } \\
\text { Ministério do Meio } \\
\text { Ambiente (MMA); } \\
\text { - relação entre despesas } \\
\text { autorizadas e despesas } \\
\text { empenhadas nos principais } \\
\text { programas do MMA; } \\
\text { - análise das despesas } \\
\text { ambientais por instituições } \\
\text { que atuam no setor. }\end{array}$ \\
\hline Borinelli & 2007 & $\begin{array}{l}1994- \\
2002\end{array}$ & - Estadual & $\begin{array}{c}\text { Total, por } \\
\text { subfunções, } \\
\text { institucional. }\end{array}$ & $\begin{array}{l}\text { Participação da despesa do } \\
\text { órgão ambiental, com e sem } \\
\text { receitas de serviços, na } \\
\text { despesa total do governo; } \\
\text { participação das despesas } \\
\text { com pessoal ativo e inativo } \\
\text { do órgão ambiental nas } \\
\text { transferências de recursos do } \\
\text { Governo do Estado; } \\
\text { participação das despesas } \\
\text { com principais subfunções } \\
\text { na despesa total do orgão } \\
\text { ambiental, relação entre } \\
\text { receitas com licenciamento } \\
\text { ambiental e despesa total do } \\
\text { órgão ambiental; evolução } \\
\text { da participação da despesa } \\
\text { de custeio e da despesa de }\end{array}$ \\
\hline
\end{tabular}




\begin{tabular}{|l|l|l|l|l|}
\hline & & & & $\begin{array}{l}\text { capital na despesa total do } \\
\text { órgão ambiental. }\end{array}$ \\
\hline
\end{tabular}

Figura 1: Síntese dos estudos sobre gestão ambiental e gastos públicos em meio ambiente no Brasil.

Fonte: Elaborado pelos autores

O primeiro estudo realizado sobre gastos governamentais no Brasil foi o do Instituto Brasileiro de Geografia e Estatística (IBGE), em 2001. Young e Roncisvalle (2002) avaliaram os gastos em gestão ambiental, utilizando a base de dados do IBGE, com o objetivo de analisar os gastos ambientais após a Conferência Rio 92. Os autores concluem que a maioria dos investimentos em gestão ambiental é realizada pelo setor público, muito embora ressaltem que no período de 1993 a 2000 esses investimentos não aumentaram. Apesar de não conseguirem consolidar todas as informações do setor público por nível de governo, essa análise pode ser considerada a mais abrangente sobre gastos ambientais no Brasil.

Young (2006) ressalta que o fato do setor público ser o principal investidor em gestão ambiental traz, como consequência, uma variação nas receitas destinadas para esta finalidade, em razão das políticas macroeconômicas, mudanças nas políticas fiscal e monetária etc, que podem implicar em cortes orçamentários nos programas governamentais, inclusive nos recursos destinados às políticas ambientais.

Santos (2004) buscou entender aspectos da estrutura de gestão ambiental no Brasil, utilizando as informações do Sistema Integrado de Administração Financeira do Governo Federal (SIAFI). Na análise da gestão ambiental avaliou aspectos da organização, das políticas ambientais, da coordenação entre os níveis de governo, entre outros. No que diz respeito à análise orçamentária, esse estudo focou os gastos do governo central, avaliando a alocação orçamentária e o valor realizado em cada exercício entre 1995 a 2002. O autor conclui que, devido às dimensões continentais do Brasil, é importante descentralizar as ações da política ambiental e a destinação de recursos específicos para a gestão ambiental nos municípios. Isso exige, de fato, maiores pesquisas sobre as dimensões fiscais do federalismo ambiental. Ante os recursos escassos em épocas de severa restrição fiscal, recomenda-se que os governos realizem uma avaliação do gasto e do investimento público ambiental.

O estudo realizado por Barcena et al. (2002) visou analisar o custo do financiamento da gestão ambiental nos países da America Latina e Caribe. Em termos gerais, revelou que a crise econômica de 1980 afetou o nível de alocação dos recursos para a área ambiental. Neste estudo são apresentados dados de gastos ambientais em nível federal, porém com recomendações para que se analisem os gastos nas esferas estaduais e municipais, sem prejuízo dos dados consolidados.

No caso do Brasil, segundo Bárcena et al (2002), os gastos ambientais realizados pelo setor público brasileiro, no ano 2000, representaram apenas $0,33 \%$ do PIB, o que equivale a US\$ 9,2 per capita.

Este estudo vem ao encontro dos resultados encontrados por Lemos, Young e Geluda (2005) ao analisarem os gastos ambientais do governo federal, utilizando dados da Secretaria do Tesouro Nacional (STN, 2010), uma vez que os autores encontraram evidências de descaso político em relação ao processo de alocação de recursos para área ambiental no Brasil.

Carneiro (2008) observou que os gastos governamentais em meio ambiente foram negativamente influenciados pelas crises da economia brasileira em 2002 e 2003, destacando a irrelevância do orçamento de órgãos públicos que administram a questão ambiental. Buscou-se, por meio deste artigo, resgatar a importância de se avaliar os gastos públicos nesta questão e seu impacto nas mudanças climáticas e na melhoria do meio ambiente, fazendo uma análise inovadora neste aspecto. $\mathrm{O}$ autor conclui que é necessário considerar os gastos em gestão ambiental, quando se quer avaliar o custo de redução de emissão de poluentes, pois estes gastos estão relacionados com a estrutura física ambiental, atendimento de demandas públicas e outras despesas necessárias à 
manutenção da estrutura governamental.

Com base nos estudos que tratam de gastos ambientais no Brasil, realizados pelo setor público, têm-se evidências de que as análises ainda estão limitadas aos gastos do governo central, embora Lemos, Young e Geluda (2005); Borinelli (2007) e IBGE/IDS (2008) apresentem análises descentralizadas.

Em síntese, as pesquisas sobre gastos ambientais no setor público brasileiro foram produzidas após o final dos anos 1990, destacando-se o nível de análise federal e as despesas totais, por função e por subfunções da gestão ambiental. Entre os indicadores usados nas análises, os mais recorrentes foram os valores absoluto e relativo por função e subfunção da gestão ambiental, a proporção entre despesa orçada e liquidada e a participação da despesa do órgão ambiental na despesa total da instância de governo. Portanto, são poucos os trabalhos mais consistentes sobre os gastos ambientais das esferas estadual e municipal, das agências ambientais e de políticas e programas específicos, o que sugere um amplo rol de temas para novas pesquisas.

No contexto internacional, têm-se estudos com outras perspectivas de análise sobre a questão dos gastos em gestão ambiental. Optou-se por sintetizar os indicadores e conclusões relevantes desses artigos no Quadro 2.

Em síntese, mesmo em nível internacional, o número de estudos sobre gastos ambientais do setor público parece ser relativamente pequeno. De maneira geral, há maior diversidade de indicadores utilizados nos trabalhos internacionais, comparativamente ao caso brasileiro. É mais frequente o uso de indicadores econômicos para analisar os gastos ambientais, com destaque para a participação dos gastos ambientais do setor público no PIB, no total dos gastos públicos e per capita. O estudo de Magnami (2000) representa um avanço em relação à mera descrição da evolução e comparação de gastos, pois, por meio de correlação, procura explicar o comportamento dos gastos ambientais em relação à desigualdade de renda. Uma importante contribuição de alguns estudos que seguem essa perspectiva é analisar os fatores que podem explicar a disposição das unidades federativas a investir em meio ambiente. Segundo Grand e D'Elia (2007), apoiados em um estudo com países da América Latina e Caribe, o grau de desenvolvimento humano (que inclui educação, esperança de vida e PIB per capita) e a pressão demográfica tendem a explicar mais a disposição dos países em investir mais em meio ambiente. Magnami (2000) estudou quais os fatores determinantes do volume de gastos em proteção ambiental em países de alta renda. Entre os fatores, averiguou como o nível desigualdade de renda influencia nos gastos ambientais, com base nos países a comunidade europeia no período de 1980 a 1991. Como resultado, há evidências de que quando há aumento da renda per capita, os habitantes de um país podem estar dispostos a pagar por melhor proteção ambiental. Contudo, a desigualdade de renda absoluta pode influenciar negativamente nos gastos ambientais, ou seja, países pobres gastam menos. Ficou comprovado que as despesas públicas com meio ambiente são afetadas pela variação da renda entre países. Quando o aumento da renda per capita em países de renda alta vier acompanhado de aumento da desigualdade, a disposição para gastos ambientais diminuem. Isto não pode ser generalizado para países com renda per capita baixa (Magnami, 2000). Essas abordagens sugerem a possibilidade de novos estudos para o caso brasileiro, como será ilustrado a seguir.

\section{EXERCITANDO PROPOSTAS ALTERNATIVAS DE ANÁLISE DE GASTOS AMBIENTAIS NO BRASIL}

Nesta seção, apresentar-se-á, a título de ilustração, algumas análises dos gastos públicos em meio ambiente a partir de informações obtidas junto à Secretaria do Tesouro Nacional (STN) e ao IBGE. O objetivo é demonstrar as possibilidades de detalhamento das informações em gestão ambiental no setor público no Brasil, disponíveis pelo aumento da transperência das informações financeiras e pelo uso do governo eletrônico. Por limites de espaço e de precocidade das investigações, não se pretendeu analisar as implicações das relações que serão apresentadas, mas

Revista de Gestão Social e Ambiental - RGSA, São Paulo, v. 5, n. 2, p. 79-95, mai./ago. 2011. 
ilustrar como essas relações abrem um amplo e provocante campo de indagações sobre a dinâmica dos gastos ambientais.

\begin{tabular}{|c|c|c|c|}
\hline Autor(es) & País/Bloco analisado & $\begin{array}{l}\text { Período de } \\
\text { análise }\end{array}$ & Indicadores utilizados \\
\hline Bárcena et al. (2002) & $\begin{array}{l}\text { Argentina, Brasil, } \\
\text { México, Trinidad } \\
\text { Tobago, Costa Rica, } \\
\text { Chile. }\end{array}$ & $\begin{array}{l}1994 \text { a } 2000 \\
1992 \text { a } 2001\end{array}$ & $\begin{array}{l}\text { - Participação dos gastos ambientais } \\
\text { do setor público no PIB; } \\
\text { - gastos ambientais per capita. }\end{array}$ \\
\hline $\begin{array}{l}\text { Gálan e Canal } \\
\text { (2002) }\end{array}$ & Colômbia & 1995 a 2001 & $\begin{array}{l}\text { - Perfil dos gastos ambientais } \\
\text { públicos e privados e o sistema de } \\
\text { coleta das informacões. }\end{array}$ \\
\hline $\begin{array}{l}\text { Dougall e Huggins } \\
\text { (2002) }\end{array}$ & Trinidad Tobago & 1993 a 1999 & $\begin{array}{l}\text { - Participação dos gastos ambientais } \\
\text { do setor público no PIB; } \\
\text { - gastos públicos ambientais per } \\
\text { capita. }\end{array}$ \\
\hline $\begin{array}{l}\text { Endara e Noboa } \\
\qquad(2005)\end{array}$ & Equador & 1995 & $\begin{array}{l}\text { - Participação dos gastos ambientais } \\
\text { do setor público no PIB; } \\
\text { - participação dos gastos públicos } \\
\text { ambientais no total do gasto } \\
\text { público. }\end{array}$ \\
\hline $\begin{array}{l}\text { Merino e Tovar } \\
\text { (2002) }\end{array}$ & México & 2000 & $\begin{array}{l}\text { - Participação dos gastos ambientais } \\
\text { do setor público no PIB; } \\
\text { - participação dos gastos públicos } \\
\text { ambientais no total do gasto } \\
\text { público. }\end{array}$ \\
\hline $\begin{array}{l}\text { Leipert, Simonis } \\
\text { (1990) }\end{array}$ & Alemanha & 1975 a 1985 & $\begin{array}{l}\text { - Participação dos gastos ambientais } \\
\text { do setor público no PIB; } \\
\text { - valor dos gastos públicos e privados } \\
\text { com reparação ambiental e } \\
\text { mecanismos de controle; } \\
\text { - estimativa do custo ambiental como } \\
\text { participação no PIB. }\end{array}$ \\
\hline $\begin{array}{l}\text { Pearce e Palmer } \\
\text { (2001) }\end{array}$ & Países da Europa e Ásia & 1996 a 1999 & $\begin{array}{l}\text { - Participação dos gastos ambientais } \\
\text { do setor público no PIB. }\end{array}$ \\
\hline $\begin{array}{l}\text { Vincent et al. } \\
\quad(2002)\end{array}$ & $\begin{array}{l}\text { Coreia do Sul } \\
\text { Indonésia } \\
\text { Tailândia }\end{array}$ & 1997 & $\begin{array}{l}\text { - Participação dos gastos ambientais } \\
\text { do setor público no PIB; } \\
\text { - participação dos gastos públicos } \\
\text { ambientais no total do gasto; } \\
\text { - gastos públicos ambientais per } \\
\text { capita. }\end{array}$ \\
\hline Magnami (2000) & $\begin{array}{l}\text { Países da União } \\
\text { Europeia }\end{array}$ & 1980 a 1991 & $\begin{array}{l}\text { - Procurou correlacionar o nível de } \\
\text { desigualdade de renda com gastos } \\
\text { ambientais. }\end{array}$ \\
\hline
\end{tabular}

Figura 2: Síntese de alguns estudos internacionais sobre gestão ambiental e gastos públicos em meio ambiente.

Fonte: Elaborado pelos autores.

A Tabela 1, a seguir, traz informações sobre os gastos ambientais realizados pelo setor público, no Brasil, no período 2002 a 2008. Observa-se uma tendência de crescimento dos gastos ambientais no período em análise, principalmente dos gastos da União. A taxa de crescimento anual calculada para o período 2002-2008 foi igual a 19,3\% a.a., 6,5\% a.a. e 18,1\% a.a, para a União, Estados e Municípios, respectivamente. Para o total dos gastos, a taxa de crescimento anual foi 
igual a $14,4 \%$ a.a., o que evidencia que os gastos em meio ambiente realizados pelos estados cresceram a uma taxa bastante inferior à calculada para as demais esferas de governo. Ao que parece, houve uma descentralização dos gastos públicos em meio ambiente da esfera estadual para a municipal. No geral, 45\% dos gastos ambientais são realizados pela União, cabendo aos estados e municípios uma participação igual a $34 \%$ e $21 \%$, respectivamente.

Tabela 1: Gastos ambientais do setor público no Brasil por nível de governo - 2002 a 2008 (em R\$ milhões).

\begin{tabular}{|c|c|c|c|c|c|c|c|}
\hline \multirow{2}{*}{ Ano } & \multicolumn{2}{|c|}{ União } & \multicolumn{2}{c|}{ Estados } & \multicolumn{2}{c|}{ Municípios } & Total dos \\
\cline { 2 - 7 } & Abs. & \% & Abs. & \% & Abs. & \% & gastos \\
\hline 2002 & $1.264,9$ & 37,3 & $1.437,8$ & 42,4 & 688,0 & 20,3 & $3.390,7$ \\
\hline 2003 & 947,7 & 26,4 & $1.751,9$ & 48,8 & 888,3 & 24,8 & $3.587,9$ \\
\hline 2004 & $1.193,4$ & 31,2 & $1.658,1$ & 43,3 & 975,8 & 25,5 & $3.827,3$ \\
\hline 2005 & $1.992,0$ & 42,6 & $1.927,7$ & 41,2 & 761,0 & 16,3 & $4.680,7$ \\
\hline 2006 & $1.497,9$ & 33,2 & $1.846,8$ & 41,0 & $1.161,9$ & 25,8 & $4.506,6$ \\
\hline 2007 & $3.145,9$ & 49,2 & $1.770,9$ & 27,7 & $1.478,2$ & 23,1 & $6.395,0$ \\
\hline 2008 & $3.639,1$ & 47,8 & $2.102,4$ & 27,6 & $1.867,7$ & 24,5 & $7.609,2$ \\
\hline Total & $13.680,9$ & - & $12.495,7$ & - & $7.820,9$ & - & $33.997,4$ \\
\hline
\end{tabular}

Fonte: Elaborada pelos autores com dados da STN (vários anos).

A participação dos gastos com gestão ambiental no PIB brasileiro ampliou-se de $0,23 \%$ do PIB em 2002 para 0,25\% do PIB em 2008, ao mesmo tempo que a participação destes gastos em relação ao total das despesas do setor público elevou-se em 0,05 pontos percentuais, passando de 0,36\% em 2002 para 0,41\% em 2008. Em relação aos gastos ambientais per capita, em 2002 gastava-se $\mathrm{R} \$ 19,22$ contra $\mathrm{R} \$ 40,3$ em 2008, o que revela uma taxa de crescimento anual (em valores correntes) igual a 15,6\% a.a., bem acima da taxa de crescimento populacional e do PIB no mesmo período. (Tabela 2)

Ao comparar os indicadores calculados para o Brasil com os divulgados pelos estudos realizados para países da América Latina (Quadro 2), verifica-se que, no Brasil, os indicadores dos gastos ambientais são maiores. No entanto, tomando como referência os indicadores da Alemanha, pode-se constatar que os calculados para o Brasil estão muito aquém.

Tabela 2: Participação dos gastos ambientais no Brasil em relação ao PIB, no período 2002 a 2008.

\begin{tabular}{|c|c|c|c|}
\hline ANO & $\begin{array}{c}\text { Gastos com gestão } \\
\text { ambiental /PIB (em } \\
\text { \%) }\end{array}$ & $\begin{array}{c}\text { Gastos com gestão } \\
\text { ambiental /despesa total } \\
\text { do governo (União, } \\
\text { Estados e Municípios) (em } \\
\text { \%) }\end{array}$ & $\begin{array}{c}\text { Gastos per capita } \\
\text { com gestão } \\
\text { ambiental (em reais) }\end{array}$ \\
\hline 2002 & 0,23 & 0,36 & 19,22 \\
\hline 2003 & 0,21 & 0,30 & 20,05 \\
\hline 2004 & 0,20 & 0,30 & 21,08 \\
\hline 2005 & 0,22 & 0,31 & 25,52 \\
\hline 2006 & 0,19 & 0,28 & 24,29 \\
\hline 2007 & 0,24 & 0,37 & 40,08 \\
\hline 2008 & 0,25 & 0,41 & 26,34 \\
\hline Média no & 0,22 & 0,33 & 43 \\
\hline período & & & \\
\hline
\end{tabular}

Fonte: Elaborada pelos autores com base nos dados do IBGE (vários anos) e STN (vários anos).

Revista de Gestão Social e Ambiental - RGSA, São Paulo, v. 5, n. 2, p. 79-95, mai./ago. 2011. 
$\mathrm{Na}$ Tabela 3, tem-se um mapeamento da alocação de recursos dos estados para gestão ambiental. Os indicadores representam a média calculada para o período de 2002 a 2009.

A observação do detalhamento dos gastos internos da parcela dos estados brasileiros (Tabela 3) revela que existe uma grande heterogeneidade na alocação de recursos para gastos ambientais. Tomando o gasto per capita, constata-se que o gasto médio no período de 2002 a 2009 é próximo de 2,0 reais por habitante no Pará, Roraima e Maranhão e mais de 15 reais em estados como Acre, São Paulo, Distrito Federal, Ceará e Rio Grande do Norte. Esta disparidade ocorre, também, quando analisamos os mesmos dados sob a ótica dos indicadores de participação dos gastos ambientais no PIB e em relação à renda.

Tabela 3: Participaçao média dos gastos ambientais do setor público estadual sobre PIB e despesas total e gastos per capita por estado no período de 2002 a 2009.

\begin{tabular}{|c|c|c|c|}
\hline \multirow{2}{*}{ Unidades da Federação } & \multicolumn{3}{|c|}{ Gastos ambientais (GA) dos Estados Brasileiros } \\
\cline { 2 - 4 } & $\begin{array}{c}\text { GA/Total } \\
\text { despesas do } \\
\text { Estado }(\%)\end{array}$ & $\begin{array}{c}\text { GA per } \\
\text { capita( } \boldsymbol{\text { }} \mathbf{} \text { ) }\end{array}$ & $\begin{array}{c}\text { GA/PIB } \\
\mathbf{( \% )}\end{array}$ \\
\hline CE & 1,82 & 17,12 & 0,37 \\
\hline RN & 0,99 & 15,79 & 0,24 \\
\hline SP & 0,91 & 18,00 & 0,10 \\
\hline SE & 0,86 & 13,83 & 0,20 \\
\hline AL & 0,76 & 6,96 & 0,18 \\
\hline AC & 0,76 & 24,19 & 0,33 \\
\hline RJ & 0,74 & 15,73 & 0,10 \\
\hline BA & 0,64 & 7,04 & 0,11 \\
\hline MT & 0,63 & 13,89 & 0,11 \\
\hline MG & 0,61 & 9,49 & 0,09 \\
\hline PR & 0,57 & 7,85 & 0,06 \\
\hline DF & 0,52 & 17,58 & 0,05 \\
\hline PI & 0,52 & 5,49 & 0,13 \\
\hline AM & 0,47 & 8,73 & 0,08 \\
\hline PB & 0,47 & 5,89 & 0,11 \\
\hline PE & 0,35 & 4,16 & 0,07 \\
\hline TO & 0,33 & 7,27 & 0,10 \\
\hline MS & 0,30 & 6,34 & 0,06 \\
\hline RO & 0,28 & 5,71 & 0,07 \\
\hline GO & 0,24 & 3,38 & 0,04 \\
\hline AP & 0,24 & 6,42 & 0,08 \\
\hline PA & 0,23 & 2,42 & 0,04 \\
\hline RS & 0,23 & 3,88 & 0,03 \\
\hline SC & 0,21 & 3,31 & 0,02 \\
\hline ES & 0,12 & 3,19 & 0,02 \\
\hline MA & 0,12 & 1,10 & 0,02 \\
\hline RR & 0,08 & 2,32 & 0,03 \\
\hline MÉDIA & 0,52 & 8,78 & 0,10 \\
\hline
\end{tabular}

Fonte: Elaborada pelos autores com dados do IBGE (vários anos) e STN (vários anos).

Ampliando o detalhamento, a Tabela 4 apresenta evidências das possibilidades de análise nos municípios brasileiros. O quadro é uma amostra com os 10 maiores municípios do estado do 
Paraná, mas pode ser aplicado ao conjunto dos municípios brasileiros.

Tomando a amostra dos 10 maiores municípios do Paraná em população, temos evidências do mesmo comportamento em relação aos estados, com a presença de diversas disparidades mais acentuadas. Esse é o caso, por exemplo, de Cascavel que investiu 7,32\% do seu orçamento em gestão ambiental, enquanto Curitiba, que já foi conhecida como a "capital ecológica" do Brasil, investiu 0,96\%. Cidades como Cascavel e São José dos Pinhais investem, per capita, só com recursos municipais, mais que a média nacional de 40 reais. Tais constatações e outras expressas nas ilustrações acima levam ao questionamento: quais fatores são mais determinantes no processo de alocação dos gastos ambientais pelo poder público?

Tabela 4: Participação média dos gastos ambientais dos 10 maiores municípios do Paraná sobre PIB e despesa total, gasto per capita e por área $\left(\mathrm{Km}^{2}\right)$ no período 2002 a 2008.

\begin{tabular}{|c|c|c|c|c|}
\hline \multirow[b]{2}{*}{ Municípios } & \multicolumn{4}{|c|}{ Gastos ambientais (GA) nos principais municípios do Paraná } \\
\hline & $\begin{array}{c}\text { GA/PIB } \\
(\text { em \%) }\end{array}$ & $\begin{array}{c}\text { GA per } \\
\text { capita (em } \\
\mathrm{R} \$ 1,00)\end{array}$ & $\begin{array}{c}\text { GA/Despesa } \\
\text { total } \\
(\text { em } \%)\end{array}$ & $\begin{array}{l}\text { GA por } K^{2} \\
(\text { em } R \$ 1,00)\end{array}$ \\
\hline 1-Curitiba & 0,08 & 14,26 & 0,96 & $57.724,38$ \\
\hline 2-Londrina & 0,17 & 23,66 & 2,51 & $6.951,76$ \\
\hline 3-Maringá & 0,05 & 7,76 & 0,85 & $5.031,56$ \\
\hline 4-Foz do Iguaçu & 0,03 & 6,26 & 0,75 & $2.880,78$ \\
\hline 5-Ponta Grossa & 0,01 & 1,58 & 0,22 & 230,08 \\
\hline 6-Cascavel & 0,41 & 47,27 & 7,32 & $6.252,57$ \\
\hline 7-São José dos Pinhais & 0,17 & 47,21 & 5,42 & $12.657,69$ \\
\hline 8-Colombo & 0,03 & 1,94 & 0,42 & $2.224,16$ \\
\hline 9-Guarapuava & 0,05 & 6,08 & 1,03 & 322,48 \\
\hline 10-Paranaguá & 0,02 & 7,00 & 0,89 & $1.193,95$ \\
\hline
\end{tabular}

Fonte: Elaborada pelos autores com dados do IBGE (vários anos) e STN (vários anos).

Uma resposta consistente a essa questão requer que se recorra, em futuras investigações, a abordagens quantitativas e qualitativas para considerar, individual e conjuntamente, a influência de fatores econômicos, sociais, políticos e geográficos, entre outros, na dinâmica dos gastos ambientais. Como exemplo, e retomando o já exposto, pode-se citar variáveis de estudo como a renda per capita, a concentração da renda, o PIB, o nível de educação, o Índice de Desenvolvimento Humano (IDH), a desigualdade social, o partido político, o grau de urbanização, a população, o grau de industrialização, a desigualdade regional e a densidade demográfica. Ademais, deve-se também considerar a possibilidade de que as disparidades constatadas resultem de diferentes interpretações na alocação dos gastos ambientais nos balanços, problema que pode ser, em parte, atribuído às características da política ambiental.

\section{PARTICULARIDADES DA POLÍTICA AMBIENTAL E GASTOS AMBIENTAIS}

Análises mais consistentes dos gastos públicos em meio ambiente devem considerar aspectos de ordem mais qualitativa que, por assim dizer, dão uma certa particularidade à política ambiental.

Uma primeira questão diz respeito à especificidade das políticas ambientais, em decorrência do seu objeto. Os problemas de sustentabilidade ambiental são significativamente diferentes da maioria dos outros problemas tratados pela política pública (por exemplo, fiscais, educação, saúde,

Revista de Gestão Social e Ambiental - RGSA, São Paulo, v. 5, n. 2, p. 79-95, mai./ago. 2011. 
prestação de serviços etc.). Algumas das particularidades da política ambiental são a escala temporal, escala espacial, incerteza, complexidade e conectividade, irreversibilidade, acumulação, urgência, dimensões morais e éticas. (Dovers, 1996). Como adverte o autor, isso não quer dizer que outras áreas sejam fáceis ou simples, mas que a sustentabilidade ambiental exige diferentes abordagens e processos. Tais atributos não são exclusivos dos problemas de sustentabilidade, nem todos os problemas de sustentabilidade apresentam todos estes atributos, mas os casos mais sérios de sustentabilidade ambiental tendem a apresentá-los com mais frequência e, mais comumente, em combinação. A transversalidade dentro do Estado e a fragmentação das ações, que têm implicações positivas ou negativas para o meio ambiente, são inúmeras e, muitas, desconhecidas. Essa complexidade dificulta a definição de um montante de gastos satisfatórios e a verificação da eficiência. Esta situação é bastante agravada nos casos, como o do Brasil, em que há quase a ausência de indicadores de qualidade ambiental.

A complexidade e a incerteza, características dos problemas ambientais, restringem a priorização da área quando na disputa com outros gastos, cuja necessidade e resultados são mais concretos e imediatos, logo, com maior apelo social e eleitoral. Esse aspecto, por sua vez, tende a justificar e legitimar, em momentos de crise, a não-alocação, cortes e contingenciamentos sistemáticos, acima da média geral, no orçamento do setor ambiental. Isso, muitas vezes, em benefício de outras áreas, que, não raro, geram sérios impactos ambientais. (Almeida, 2006; Young, 2006).

Outro atributo, certamente não exclusivo da política ambiental, mas que nesse campo é por demais saliente, é o alto grau de conflito que os problemas e as decisões ambientais encerram.

A análise dos gastos ambientais no Brasil, como em outros países em desenvolvimento, quase invariavelmente está revestida de um caráter de denúncia e de reivindicação. (Lemos, Young \& Geluda, 2005; Santos, 2004). Os estudos reivindicam maior alocação de recursos no setor e denunciam o descaso para as necessidades ambientais e a marginalização das políticas ambientais. A constatação da debilidade da política ambiental é um tema recorrente em trabalhos nacionais e internacionais e quase sempre é determinada pelos conflitos, contradições e ameaças que as políticas ambientais representam para as estruturas políticas, econômicas e sociais das atuais sociedades (Guimarães, 1988; Borinelli, 2007). Discutir se essas restrições são ou não intransponíveis exigiria um outro artigo, mas o que se pode afirmar é que, em grande medida, elas compremetem consideravelmente a autonomia e a capacidade de ação das agências ambientais, imprimindo à política ambiental um status de política negativa. Com o desmantelamento dos órgãos ambientais, no Brasil, na década de 1990 (Neder, 2002), assistiu-se não só ao estacionamento ou à redução do orçamento dos órgãos ambientais, mas também à redução e desqualificação do quadro de técnicos ambientais. Em Santa Catarina, por exemplo, recursos captados por meio de convênio internacional foram devolvidos por falta de pessoal para elaborar projetos específicos. (Borinelli, 2007). Outro importante fator a interferir na efetividade dos gastos ambientais do setor público é a corrupção. Uma corrupção sistêmica (Martins, 1995) tende a mediar boa parte das relações que envolvam recursos de poder, comprometendo, pela apropriação privada de recursos públicos, as fontes de receitas e a destinação destes recursos. Portanto, não se trata apenas de alocar mais recursos para o setor, mas também de rever a capacidade administrativa e a autonomia das agências ambientais.

Os recursos insuficientes e a fragilidade institucional do setor ambiental são indicadores essenciais do lugar da política ambiental no Estado e na sociedade (Goldblatt, 1996). Assim, do ponto de vista metodológico, a politização dos gastos ambientais pode ser um recurso analítico para denunciar a marginalização e o descaso com as necessidades das políticas ambientais, como para investigações qualitativas mais consistentes. A análise de gastos públicos em uma determinada área permite rastrear o lugar do setor e das instituições na estrutura de poder estatal e social. Por meio dela, é possível monitorar, comparativa e historicamente, as oscilações em termos do tratamento e das prioridades entre as instituições ambientais, os setores governamentais, os governos, os ciclos 
eleitorais, os partidos, os grupos de poder, personalidades e os períodos históricos. Portanto, os gastos ambientais expressam uma síntese de processos de distribuição de poder na sociedade e no Estado. A sua análise pode oferecer uma avaliação parcial e, quando cotejada com outras dimensões analíticas, mais profunda e extensa, da política pública e dos processos políticos em uma determinada unidade geográfica.

\section{CONSIDERAÇÕES FINAIS}

Neste artigo, buscou-se chamar a atenção para a necessidade e a possibilidade de um maior número de estudos sobre as potencialidades e limitações da análise de gastos públicos em meio ambiente.

Diante das crescentes ameaças relacionadas à degradação ambiental, nas últimas décadas, têm crescido a preocupação em se analisar os gastos ambientais, como forma de avaliar a dinâmica de tais gastos e a efetividade da política ambiental. De um modo geral, os estudos nacionais e internacionais sobre este tema têm refletido essa preocupação ao priorizarem a mensuração destes gastos e a definição de um montante ideal, tomando como referência, principalmente, indicadores econômicos e comparações da despesa do setor com a despesa total de países e estados. Comparações sincrônicas e diacrônicas e, em menor grau, tentativas de explicar os fatores que mais determinam os gastos ambientais e seus impactos também têm caracterizado esses estudos.

É possível avançar consideravelmente na análise quantitativa e qualitativa dos gastos ambientais brasileiros. Para isso, os esforços devem voltar para a monitorar os gastos e sua eficiência, mas também de definir critérios para estimar montantes ideais de gastos e de compreender a dinâmica dos gastos ambientais, por exemplo, com a análise correlacional de variáveis econômicas, sociais, políticas e territoriais. Também, a compreensão de tal dinâmica exige que se aprecie, numa perspectiva histórica e comparativa, a especificidade e a dimensão política da política ambiental. A análise da eficiência dos gastos requer necessariamente que se enfrente uma séria deficiência da política ambiental brasileira, que é a quase inexistência de indicadores de qualidade ambiental e de sustentabilidade confiáveis e sistemáticos. Seguindo essa e outras perspectivas, será possível compreender melhor a dinâmica dos gastos ambientais num determinado período, ao longo do tempo, entre países e, internamente, entre estados e municípios.

A coleta e a análise dos gastos ambientais dos setor público, no Brasil, foram sensivelmente falicilitados com as adequações na contabilidade pública e a Lei de Responsabilidade Fiscal. Contudo, deve-se observar que possíves disparidades acentuadas entre os dados informados podem esconder uma falta de uniformidade no entendimento das definições e abrangências de funções e subfunções ambientais, principalmente nos estados e municípios.

Embora a análise dos gastos ambientais seja um recorte importante para se compreender o financiamento da política ambiental, uma abordagem mais completa desse problema deveria também considerar o processo que antecede e sucede este gasto, como o processo de composição das receitas e o processo orçamentário, a capacidade institucional dos órgãos ambientais e a efetividade dessas despesas na resolução dos problemas ambientais.

Com a exposição realizada, espera-se ter demonstrado que um maior número de pesquisas sobre gastos ambientais é necessário e possível no atual contexto. Neste conexto, um campo de investigações com debates mais fecundos e vigorosos sobre a análise de gastos ambientais será essencial para o uso mais efetivo de dados públicos na avaliação crítica e social da política ambiental e para a promoção de sua maior efetividade. 


\section{REFERÊNCIAS}

Abranches, S.(1987). Governo, empresa estatal e política siderúrgica: 1930-1975. In: Lima Jr, O. B. de \& Abranches, S. H. (Coord.). As origens da crise: Estado autoritário e planejamento no Brasil. São Paulo: Vértice, Editora Revista dos Tribunais.

Almeida, J.R.de. (2006). Gestão ambiental para o desenvolvimento sustentável. Rio de Janeiro: Thex Ed.

Bárcena, A., Miguel, C. J. de, Núnez, G., Gómez, J. J., Acquatella, J., Acuña, G. (2002). Financiamiento para El desarrollo sostenible en América Latina y el Caribe De Monterrey a Johanesburgo. Santiago del Chile. Organização das Nacões Unidas - Comisión Económica para América Latina - CEPAL.

Borinelli, B. (2007). Desempenho político-administrativo das instituições ambientais na década de 1990: a experiência da fundação do meio ambiente de Santa Catarina - FATMA. Tese de Doutorado em Ciências Sociais. Universidade Estadual de Campinas. Campinas, São Paulo, Brasil.

Bustamante, M. I., \& Torres, S. (1990, Agosto). Elementos para uma política ambiental eficaz. Revista de la CEPAL, (41), 109-122.

Carneiro, P. E. A.(2008). Modelo de mudanças climáticas com gastos públicos. Contexto Internacional. Rio de Janeiro, 30, 49-88. Recuperado em 15 de março, 2010, de http://www.scielo.br/pdf/cint/v30n1/02.pdf.

Diamond, J. (2005). Colapso: como as sociedades escolhem o fracasso ou o sucesso. Rio de Janeiro: Editora Record.

Dougall, D., \& Huggins, W. (2002). Expenditures, investment and financing for sustainable development in Trinidad and Tobago. Santiago del Chile: Organização das Nacões Unidas Comisión Económica para América Latina - CEPAL.

Dovers, S.R. (1996). Sustainability: demands on policy. Jornal of Public Policy, 16(3), 303-318.

Dutra, R. C. D., Oliveira, A. B., \& Prado, A. C. A. (2006, Setembro). Execução orçamentária do Ministério do Meio Ambiente entre 2000 e 2005. Revista Política Ambiental, Belo Horizonte, (2).

Endara, N. G., \& Noboa, S. J. (2005). El financiamiento del desarrollo sostenible en El Ecuador. Santiago del Chile: ORGANIZAÇÃO DAS NACÕES UNIDAS - Comisión Económica para América Latina - CEPAL.

Gálan, F. A., \& Canal, F. J. (2002). Gasto, inversión y financiamiento para El desarrollo sostenible en Colombia. Santiago del Chile: Organização das Nacões Unidas - Comisión Económica para América Latina - CEPAL.

Gestão do Dinheiro Público. Balanço Geral do Estado (2003 a 2008). Recuperado em 14 agosto ,2009, de http://www.gestaodinheiropublico.pr.gov.br/Gestao/balanco/balanco.jsp

Giambiagi, F., \& Além, A. C.(2007). Finanças públicas - Teoria e Prática no Brasil. (3.ed.) Rio de Janeiro: Ed. Campus. 
Goldblatt, D. (1996). Teoria social e ambiente. Trad. Ana Maria André. Lisboa: Instituto Piaget.

Grand, M. C., \& D'elia, V. (2007). La política ambiental en América Latina y el Caribe: ¿de qué depende?. CEMA Working Papers: Serie Documentos de Trabajo. 366, Universidad del CEMA. Recuperado em 20 maio, 2010, de http://ideas.repec.org/f/pde271.html.

Guimarães, R. (1988). Ecologia e política na formação social brasileira. Revista de Ciências Sociais, Rio de Janeiro, 31(2).

IBGE - Instituto Brasileiro de Geografia e Estatística. (2001). Despesas públicas por funções 19961998. IBGE: Rio de Janeiro.

. Indicadores de Desenvolvimento Sustentável - Brasil. (2008). Estudos e pesquisas informação geográfica, (5). IBGE: Rio de Janeiro.

Jasch, C. (2003, September). The use of environmental management accounting (EMA) for identifying environmental costs. Journal of Cleaner Production, 11, p. 667- 676. Recuperado em 23 março 2010, de http://www.sciencedirect.com/science/article/B6VFX-478B44W8/2/7f08d72c690337abbeddb576b79b97e4

Leipert, C., \& Simonis, U. E. (1990). Environmental Protection Expenditures-The German Example.The Environmentalist, Berlin-Germany, 10(4), 301-304. Recuperado em 21 março, 2010, de http://www.springerlink.com/content/7274491u7542t667/.

Lemos, R. A. B., Young, C. E. F., \& Geluda, L. (2005). Orçamento público para gestão ambiental: uma análise voltada para as áreas protegidas. In: Simpósio de Áreas Protegidas, 3. Pelotas-RS. Recuperado em 20 março, 2010, de http://www.ie.ufrj.br/gema/pdfs/2005-2.pdf

Loureiro, M. R., Teixeira, M. A. C., \& Prado, A.(2008) Construção de instituições democráticas no brasil contemporâneo: transparência das contas públicas. Organizações \& Sociedade, 15(47), 107-119.

Magnami, E. (2000, March). The environmental kuznets curve, environmental protection policy and income distribution. Ecological Economics, 32, 431-443. Recuperado em 23 março 2010, de http://www.sciencedirect.com/science/article/B6VDY-3YN3BXH-

H/2/edecfdc153cd5880c08436b59842ab47

Martins, L. (1995). Reforma da administração pública e cultura política no Brasil: uma visão geral. Brasília: ENAP.

Merino, G., \& Tovar, R.(2002). Gasto, inversión y financiamiento para El desarrollo sostenible en México. Santiago del Chile: ORGANIZAÇÃO DAS NACÕES UNIDAS- Comisión Económica para América Latina - CEPAL.

Monosowski, E. (1989, Junho) Políticas ambientais e desenvolvimento no Brasil. Cadernos FUNDAP, São Paulo, 9(16), 15-24.

Neder, R. T. (2002). Crise socioambiental: Estado \& sociedade civil no Brasil (1982-1998). São Paulo: Annablume.

O’Donnell, G. (2008, Outubro). Algunas reflexiones acerca de la democracia, el Estado y sus múltiples caras Revista del CLAD Reforma y Democracia. Caracas, (42). 
Ortiz, R. A., \& Ferreira, S. F. (2004). O papel do governo na preservação do meio ambiente. In: Arvate, P. R. Economia do Setor Público. Rio de Janeiro: Eselvier.

Pearce, D.,\& Palmer, C.(2001, December). Public and private spending for environmental protection: a cross-country policy analysis. Fiscal Studies, 22, 403-456. Recuperado em 15 março 2010, de http://www.ifs.org.uk/fs/articles/0048a.pdf

Rezende, F. (2001). Finanças Públicas. (2.ed.) São Paulo: Editora Atlas.

Santos, J. J. B. dos. (2004). A coordenação entre as políticas fiscal e ambiental no Brasil: a perspectiva dos governos estaduais. Santiago del Chile: Organização das Nacões Unidas Comisión Económica para América Latina - CEPAL.

Secretaria do Orçamento Federal (SOF) .Conceitos orçamentários. Recuperado em 01 julho ,2009, de https://www.portalsof.planejamento.gov.br/bib/MTO/ComponenteConceitosOrcamentarios.pdf

Secretaria do Tesouro Nacional (STN, 2010). Sistema de coleta de dados contábeis de Estados e Municípios - SISTN. Recuperado em 23 fevereiro, 2010, de http://www.tesouro.fazenda.gov.br/estados_municipios/sistn.asp

Vincent, J. R. (2002, April) et al. Public environmental expenditures in Indonesia. Bulletin of Indonesian Economic Studies, 38, 61-74. Recuperado em 20 de março ,2010, dehttp://wwwwds.worldbank.org/servlet/WDSContentServer/WDSP/IB/2001/08/29/0000949460 1081504110225/Rendered/PDF/multi0page.pdf

Young, C. E. F. (2006). Instrumentos econômicos para o desenvolvimento sustentável: o caso brasileiro. In: Parreira, C., Alimonda, H. (Org). As instituições financeiras públicas e o meio ambiente no Brasil e na América Latina. Brasília: FLACSO-Brasil, 221- 242.

\& Roncisvalle, C. A. (2002). Mecanismos de financiamento para a conservação no Brasil. $\begin{array}{lllll}\text { Recuperado em } & 29 & \text { março, } & \text { 2010, }\end{array}$ http://www.conservation.org.br/publicacoes/files/27_Carlos_Eduardo.pdf

Data do recebimento do artigo: 26/11/2010

Data do aceite de publicação: 03/08/2011 